\title{
Clinical Endocrinology
}

\section{Diabetes Insipidus}

\author{
T. D. R. HOCKADAY
}

British Medical fournal, 1972, 2, 210-213

In 1794 Frank $^{1}$ described diabetes insipidus as "a long continued abnormally increased secretion of non-saccharine urine not caused by renal disease," so distinguishing it from diabetes mellitus and the polyuria of chronic renal failure. In contrast, the definition of diabetes insipidus now usually given is of "a rare disease, characterized by polyuria and polydipsia, which results from lack of the antidiuretic hormone, arginine vasopressin". ${ }^{2}$ The latter excludes not only habitual excessive (compulsive) water drinking, ${ }^{3}$ or potomania, but also functional renal defects, as occur with hypokalaemia or hypercalcaemia, or even the inherited defect that prevents vasopressin acting effectively on the renal tubules (the so-called nephrogenic diabetes insipidus).

This definition is the most useful for recognizing those in need of vasopressin treatment (or trial of one of the oral agents that can sometimes replace it). But this article will also consider the whole clinical problem of excessive thirst and polyuria, not least because of the circular relationship between the two prime symptoms and states of hydration (see Figure, outer circle) and because of the inter-locking relationship in which over-hydration both lowers the circulating vasopressin and reduces its renal activity, so mimicking "deficiency" and "nephrogenic" diabetes insipidus, respectively (Figure, inner left). Hence, diagnosis of habitual water drinking from diabetes insipidus may be impossible without an initial period of fluid restriction.

\section{Differential Diagnosis of Thirst and Polyuria}

These complaints are easily understood, but not always emphasized by patients, and inquiry about excessive thirst is easily omitted from routine questioning. As with any symptom, it is important to get some idea of its degree. Patients complaining strongly of "thirst" because of salivary gland disease may drink less than 31 . daily. Urinary frequency alone is usually easily distinguished from polyuria because of the lack of polydipsia and the realization by the patients that they pass only small volumes of urine at a time.

Once the symptoms are established simple ward or laboratory tests on urine or blood probably carry one furthest in narrowing the diagnostic field. Nevertheless, as always, history and examination may give important leads-for example, the weight loss of diabetes mellitus; a history of "stones and groans" in hyperparathyroidism; muscle weakness in hypokalaemia; or the unusual "life situation" common in habitual water drinking. Pathognomonic features are few, however, but include visual field defects from a craniopharyngioma or the strong family history (among males) of hereditary nephrogenic diabetes insipidus.

The Radcliffe Infirmary, Oxford

T. D. R. HOCKADAY, D.PHIL., F.R.C.P., Consultant Physician

When the results of screening tests (Table I) show no explanation for polyuria and polydipsia, further investigation of the patient is needed. This will often require hospital admission, for even if the $x$-ray film of the pituitary fossa is abnormal the nature of the lesion will have to be determined, the pituitary function assessed, and the patient's response to treatment determined.

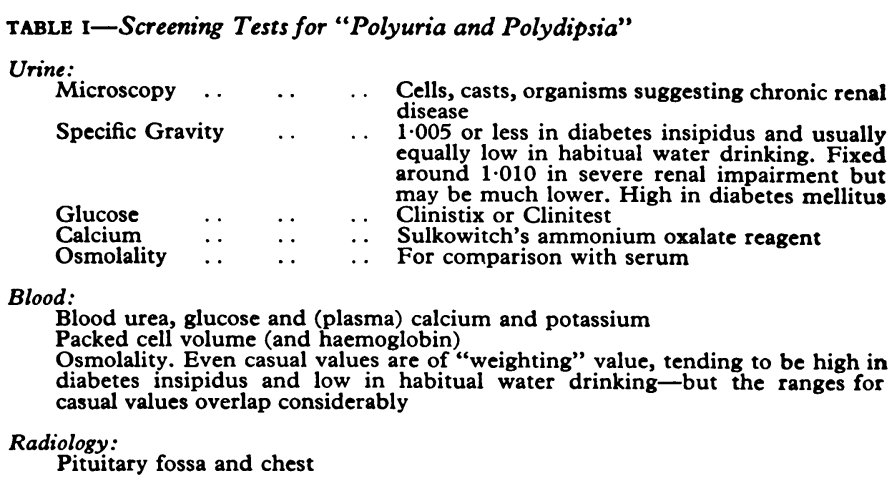

\section{Clinical Features}

Vasopressin deficiency is divided into primary and secondary groups. ${ }^{4}$ The primary group has two divisions. The first type is idiopathic deficiency, which is a common cause of this rare disease. It affects the sexes equally and may begin at any age after infancy, and histologically is associated with a striking reduction in the number of neurones in the supraoptic and paraventricular hypothalamic nuclei. ${ }^{5}$ The second type is a very rare familial type affecting both sexes, often having an onset in infancy and again being associated with a great reduction of neurones in the two nuclei.

By contrast, the secondary group includes lesions of the posterior pituitary or of the pituitary stalk. Tumours of the pituitary itself (most often chromophobe adenomas) or craniopharyngiomas still comprise most of this group. Rupture of the pituitary stalk secondary to trauma as from a car accident is now becoming increasingly frequent; in this case anosmia (at least on one side) may also be present. Iatrogenic diabetes insipidus is another cause being increasingly seen, now that operation on primary pituitary tumours is undertaken more readily and hypophysectomy is used to treat disseminated carcinoma. Other causes of the secondary group are listed in Table II.

TABLE II-Classification of "True" Diabetes Insipidus

Primary

Secondary

\section{(1) Idiopathic}

(1) Pamilial

(2) Craniopharyngiomata; other tumours adjacent to pituitary or hypothalamus or hypothalamus

(4) Traumatic, including birth injury

(5) Granulomata (sarcoidosis, eosinophilic granuloma, brucel-

(6) Rarely associated with Sheehan's syndrome; and sickle-cell disease 
Patients with secondary deficiency of vasopressin are likely to show the clinical features of the underlying disease process. Patients with habitual excessive water drinking frequently have a history of psychiatric disturbance or suggestive of Munchausen's syndrome, and are usually women; the onset is often between 35 and 59, though in a few cases it is around puberty and adolescence. ${ }^{3}$ Polyuria is often erratic and also unlike that of diabetes insipidus in being gradual or "stuttering" in its onset. The patients may be frankly inventing the situation, or at least embellishing it, by pouring their drinking water into the bed-pan or, less ambitiously, just down the drain. Even without such help, however, the fluid turnover in habitual water drinking is classically greater (often over 101 . day and ranging up to even 30 or 401 .) than in diabetes insipidus (when it is usually between 5 and 10 1./day). Patients with diabetes insipidus, unlike those with other types of polyuria, are said by American workers to have an outstanding preference for iced drinks, ${ }^{6}$ but this is unlikely to be a world-wide feature.

Even so, patients with true diabetes insipidus are inclined to show obsessive compulsive rituals, ${ }^{7}$ and polydipsia may persist even in adequately treated patients. ${ }^{8}$ Rarely, too, lesions at the base of the brain cause primary polydipsia (see Figure), though more commonly these abolish thirst. ${ }^{10}$

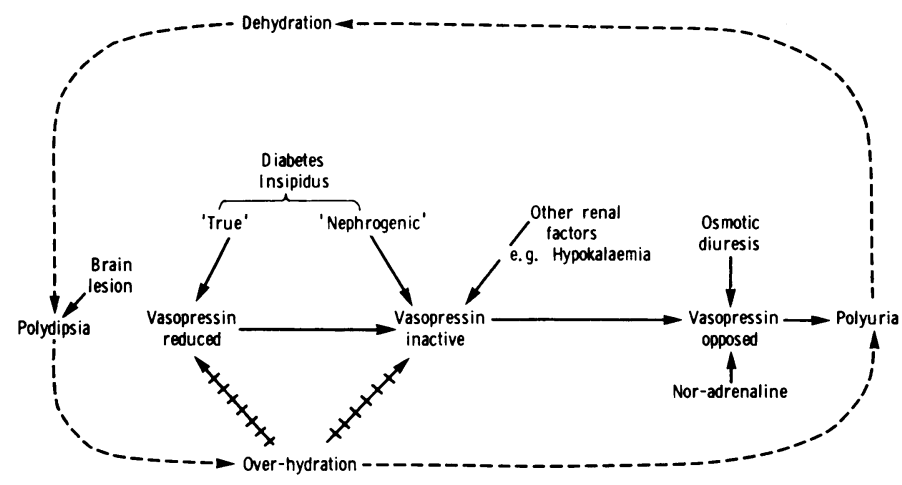

INTER-RELATED FACTORS INVOLVING VASOPRESSIN SECRETION \& ACTIVITY

Inter-related factors involving vasopressin activity and diabetes insipidus (hatched lines indicate how overhydration mimics features of diabetes insipidus).

\section{PREGNANCY}

Diabetes insipidus and pregnancy are a rare combination ${ }^{11}$ and the severity of the former may be unchanged, or vary in either direction during pregnancy. The outcome of pregnancy may be entirely normal but there is almost certainly an increased incidence of complicated pregnancies. The onset of labour and lactation, both normally involving the other peptide normally produced by the posterior pituitary, oxytocin, may be completely normal, ${ }^{12}$ but sometimes there is uterine inertia or failure of lactation. ${ }^{11}$ Diabetes insipidus occurs in Sheehan's syndrome ${ }^{13}$ only very occasionally.

\section{Investigation}

Exact diagnosis of diabetes insipidus is hampered by lack of a sensitive and reliable assay for vasopressin.

The radioimmuno-assays described so far $^{14}$ cannot reliably detect vasopressin at the usual circulating concentration, which is about $1 \mu \mathrm{U} / \mathrm{ml}$ plasma (about $2.5 \mu \mathrm{g} / \mathrm{ml}$ ). Unfortunately, too, though the bioassay is sensitive to $0.5 \mu \mathrm{U} / \mathrm{ml}$ plasma it is too capricious and tedious to be satisfactory. ${ }^{16}$ So while bioassay and immunoassay both show increased vasopressin concentrations after haemorrhage, for example, they are of little general use yet in diagnosis of a deficiency disease.*

Hence demonstration of deficient vasopressin secretion has turned to indirect methods, which mostly show a failure to produce sufficiently concentrated urine in circumstances when it would normally be

* A useful immunoassay applicable to urine (after extraction) has recently been developed. formed. An important background to some of the tests is that the normal person, when dehydrated, forms urine of greater osmolality than after a large injection of vasopressin given when he is normally hydrated. ${ }^{3}$

\section{WATER DEPRIVATION}

It must be realized that a dangerous degree of dehydration may occur surprisingly quickly (and with surprisingly little outcry from the patient) in diabetes insipidus. Hence the patient must be weighed at the outset, and the test be stopped if $3 \%$ of the body weight is lost. Urine concentration is measured at the beginning and end of the test, and superficially one is searching for the ability to concentrate urine and decrease its flow. But any absence of these features is meaningless if the patient has not lost weight and shown an increase in heamatocrit value or plasma protein concentration (or more reliably in plasma osmolality).

It is a moot point at what time prolonged fluid deprivation should begin, so that the doctor himself can make the most important observations. In practice, if habitual water drinking or mild diabetes insipidus is suspected, it is best to start around 10 p.m. (even if this increases the chances of manipulation of at least a first test by a water addict), while if severe diabetes insipidus is likely it is best to begin around 8 a.m. A normal subject may be expected to reduce the urine flow to under $0.5 \mathrm{ml} / \mathrm{min}$ and the urine osmolality to above $800 \mathrm{mOsm} / \mathrm{Kg}$ (or a specific gravity over 1020).

Shorter periods (for example, 8 or $6 \frac{1}{2}$ hours) of deprivation have been suggested, ${ }^{17} 18$ but the results may not be clear cut. Barlow and de Wardener ${ }^{3}$ relied much more on the comparison between the urine concentration after 24 hours' fluid deprivation (or loss of $3 \%$ of the body weight) and after an intravenous injection of 100-200 mU aqueous vasopressin, preferably followed by continuous infusion of $5 \mathrm{mU} / \mathrm{min}$ for one hour. In diabetes insipidus the later procedure gives the greater concentration.

Another effective test also combines the effects of dehydration and vasopressin. ${ }^{19}$ In people deprived of fluids urine is collected hourly until its osmolality is constant, when plasma osmolality is measured, and $5 \mathrm{U}$ aqueous vasopressin injected subcutaneously. Urine is collected again $60 \mathrm{~min}$. after this injection. Only 6 out of 32 normal people were found to show any increase in urine osmolality after vasopressin, and then never more than $5 \%$. But in 19 patients with a previous diagnosis of diabetes insipidus the urine initially never became more concentrated than the plasma, though after vasopressin osmolality increased by at least $50 \%$. This test distinguished another group, probably with a milder degree of "true" diabetes insipidus, in whom urine osmolality exceeded that of plasma in the initial phase and in whom vasopressin then further raised urine osmolality by a mean of $28 \%$ (minimum rise $9 \%$ ). Another "partial" group, who also showed a substantial increase after vasopressin, showed a decline in urine osmolality late in the dehydration phase, possible through exhaustion of limited stores of vasopressin.

\section{INTRAVENOUS HYPERTONIC OR ISOTONIC SALINE}

First used by Hickey and Hare ${ }^{20}$ this procedure has also often been modified. After giving an initial intravenous injection of glucose solution (usually $8-10 \mathrm{ml} / \mathrm{min}$ ) to produce a diuresis at a rate about $5 \mathrm{ml} / \mathrm{min}, 2.5 \%$ sodium chloride is given intravenously for $45 \mathrm{~min}$ at a rate of $0.25 \mathrm{ml} / \mathrm{min} / \mathrm{Kg}$ body weight - that is, about $650 \mathrm{ml}$ for the average patient. Urine is voided every 15 minutes. Normal people show a drop in the rate of urine production to below $25 \%$ of the initial rate. The procedure is faulty because the considerable sodium chloride load (about $280 \mathrm{mMoles}$ ) may cause a substantial osmotic diuresis, while the saline load is unacceptable if there is a risk of cardiac disease.

\section{NICOTINE INJECTION}

Nicotine can be injected intravenously (from 0.5 to $3.0 \mathrm{mg}$ of nicotine base, depending on habitation to tobacco) or inhaled as tobacco smoke during diuresis induced by drinking water. The diuresis should then be appreciably reduced by the normal vasopressin production and urine concentration rise correspondingly. Hypotension or even syncope induced by the nicotine may give a drop in glomerular filtration, with a sharp drop in urine flow but without marked increase in urinary 
concentration. Nevertheless, nicotine is often a more potent stimulus to vasopressin release than plasma hypertonicity, ${ }^{21}$ though unfortunately nicotine for intravenous injection is now extremely difficult to obtain in this country.

\section{ROUTINE OF STUDIES}

A recommended routine for investigation of suspected diabetes insipidus is given below (see Table I).

(1) Tests as in Table I. Random urine and plasma osmolality.

(2) 24-hour fluid intake and output during unrestricted access to fluid. Measure early morning plasma and urine osmolality.

(3) Fluid deprivation test for six hours, ${ }^{17}$ after sleep and four hours standardized fluid intake.

(4) If doubt of diagnosis remains use:

(a) Procedure of Miller et al. ${ }^{19}$ and

(b) Procedure of Barlow and de Wardener ${ }^{3}$ or both, and

(c) Retest after achieving diminished fluid turnover for two weeks

(5) If failure of vasopressin activity diagnosed by (3) or (4) test response to vasopressin, 5 IU SC to distinguish nephrogenic from intracranial causes.

Before launching more complex tests it is always worthwhile to obtain random urine and plasma samples for osmolality, since fundamentally diabetes insipidus is a dehydrating condition and compulsive water drinking one that dilutes body fluids." The 24-hour fluid balance during unrestricted access to fluid should also be recorded, with measurement of the overnight osmolalities-for surprising results may be found which make the physical problem appear much less than one had supposed.

Finally, it must be realized that initial tests may not give conclusive answers-either because of a partial defect in vasopressin production or a temporary result of over-hydration. ${ }^{22}$ Hence by a regimen of partial fluid restriction (for example, to 21 ./day), or with the help of a course of vasopressin, the doctor should try to achieve something akin to a normal fluid balance in the patient for at least two weeks before retesting.

\section{Treatment}

The conventional treatment of diabetes insipidus is by replacement of vasopressin. Unfortunately, this cannot be taken by mouth, but is available for intramuscular or intravenous injection, or it can be absorbed through the nasal mucosa. Perhaps because of this inconvenience of administration, a variety of oral agents have now been found to ameliorate diabetes insipidus, by mechanisms not wholly understood.

Aqueous vasopressin has too short an action to be acceptable for long-sustained treatment. It is used in diagnosis and is of great value in treating a rapidly changing clinical picture when the patient is in hospital-for example, after a head injury or an operation on a pituitary tumour-since in these situations phases of diuresis and antidiuresis may rapidly succeed one another. A typical intramuscular dose is from 0.5 to $0.1 \mathrm{IU}$, which acts for 1 to 2 hours. It may also be usefully added to an intravenous infusion.

Vasopressin tannate in oil is given intramuscularly-in principle as required, though often an injection once every 24 to 48 hours copes well. If the next injection is taken before polyuria has returned there is a risk of water intoxication. To achieve a reliable dosage the suspension must be warmed to blood heat and shaken thoroughly before injection. The injection site should be varied regularly, or else a large subcutaneous depot accumulates, mostly of oil, which acts as a buffer to reliable absorption. Vasopressin tannate is a satisfactory agent, to which resistance rarely develops, in contrast to the nasal preparations, whose efficacy (however convenient) often survives for only five to ten years at the most.
The resistance partly depends on the development of atrophic rhinitis secondary to the vasoconstrictive action of the drug, but use of posterior pituitary powder as snuff may also lead to attacks of brochospasm through sensitization.

\section{LYSINE VASOPRESSIN}

Lysine vasopressin is available as a spray $(5 \mathrm{ml}$ to the bottle, $50 \mathrm{IU} / \mathrm{ml}$ ) taken as one or two sniffs up each nostril; these often need to be repeated every two to four hours. Its action may be prolonged by inserting a pledget of cotton wool soaked in the solution into a nostril, but even then it rarely lasts a night through. Lysine vasopressin is also absorbed through buccal or vaginal mucosa. Though relatively costly and resistance often develops within a few years, it is clearly a real convenience and may be very useful as a standby at special times, as on a journey.

The oral agents ${ }^{23}$ for treating diabetes insipidus are now a motley bunch. The thiazides, in conventional doses, reduce polyuria in both "deficiency" diabetes insipidus and the inherited nephrogenic form. No one has yet explained exactly how they act but their effects may resemble those produced by dietary sodium deprivation or failure of the anterior pituitary (when there is decrease in appetite and a reduction in the filtered solute load.) Not unexpectedly, therefore, the related furosemide and the unrelated ethacrynic acid have both relieved diabetes insipidus.

\section{SULPHONYLUREAS}

Though it has some chemical similarity, chlorpropamide ${ }^{2 s}$ acts differently from the thiazides, and is of no help in nephrogenic diabetes insipidus. Given intravenously, chlorpropamide acts rapidly, but the usual oral dose takes 24 hours to begin to work, and 72-96 hours to be fully effective; its action wears off equally slowly. Its activity in diabetes insipidus is not shown equally by other sulphonylurea hypoglycaemic agents tested. It augments the effect of inadequate amounts of vasopressin, ${ }^{28}$ and may therefore be ineffective when vasopressin is completely absent. Water restriction increases the effectiveness of chlorpropamide, while ethanol nullifies it. Not surprisingly, therefore, hyponatraemia can occur during chlorpropamide treatment if it "over-amplifies" the effect of the amount of vasopressin present (which in partial lesions of the posterior pituitary might vary considerably). Such hyponatraemia - or indeed any manifestation of water intoxication during treatment-can occur only if the patient drinks fluid by custom rather than in response to thirst. Indeed, the patient with diabetes insipidus can never come to harm, treated or untreated, if he follows the maxim "drink whenever, but only whenever, you are thirsty", unless the mechanisms subserving thirst are working normally. Sometimes, indeed, these mechanisms are disrupted by the lesions responsible for the diabetes insipidus, and then drinking must again become a matter of habit.

It seems reasonable to expect that if intramuscular vasopressin and chlorpropamide were combined the frequency of injections (or their size) could be reduced, but there is little experience of how smoothly this combination would act or how severely fluid intake would have to be restricted on the day of the vasopressin injection.

\section{OTHER AGENTS}

Two other agents have, perhaps unexpectedly, also proved effective against diabetes insipidus. These are, firstly, Tegretol ${ }^{23}$ (carbamoyl-dibenzo-azepine), $200 \mathrm{mg}$ two to four times daily, taking 24-48 hours to begin to act, potentiated by chlorpropamide, working despite ethanol ingestion, and ineffective with nephrogenic patients. Secondly, clofibrate, ${ }^{23} 500 \mathrm{mg}$ four times 
daily, again takes two to three days to work and is also useful only when some vasopressin is present.

On present limited experience the best of the oral agents would seem to be chlorpropamide, which is effective in reducing symptoms to an acceptable level in one-third to one-half of patients. Its use is associated with a small incidence of sensitivity reactions and gastrointestinal symptoms; a low, but definite incidence of serious blood dyscrasia (it should never be used in a dose above $500 \mathrm{mg}$ a day); a liability to attacks of flushing and fainting after alcohol; and occasional occurrence of hypoglycaemia-perhaps particularly to be expected in those tending to "reactive hypoglycaemia," especially if this is an early manifestation of "maturity-type onset" diabetes mellitus.

\section{Prognosis}

This is excellent for life, unless affected by a "secondary" cause of the diabetes insipidus. The condition is perhaps less often permanent than is usual with endocrine deficiency states, and trial of cessation of therapy after, say, two and again five years should be attempted in this condition-which is essentially a "nuisance" one-provided proper watch is then kept for the effects of an acquired "polydipsic drive."

\section{References}

1 Frank, J. P., quoted by Fitz, R., Archives of Internal Medicine, 1914, 14,

' Coggins, C. H., and Leaf, A., American fournal of Medicine, 1967, 42, 807.
3 Barlow, E. D., and de Wardener, H. E., Quarterly Fournal of Medicine, $1959,28,235$.

'Randall; R. V., Clark, E. C., and Bahn, R. C., Proceedings of the Staff Meetings, Mayo Clinic, 1959, 34, 299.

Green, J. G., Buchan, G. C., Alvord, E. C., and Swanson, A. G., Brain, $1967,90,707$.

- Thomas, W. C., Jr., fournal of Clinical Endocrinology and Metabolism, $1957,17,565$.

'Barton, R., Lancet, 1965, 1, 133 and 1072.

- Stevko. R. M., Balsley, M., and Segar, W. E., fournal of Pediatrics, 1968,

$73,845$.
Kourilsky, R., David, M., Sicard, J., and Galey, J. J., Revue Neurologie, $1942,74,264$.

${ }^{10}$ Mahoney, J. H., and Goodman, A. D., New England Fournal of Medicine, $1968,279,1191$.

11 Stephens, C. O., and Hayes, O. J., Obstetrics and Gynecology, 1968, 31, 79.

12 Chau, S. S., Fitzpatrick, R. J., Jamieson, B., fournal of Obstetrics and Gynaecology of the British Commonwealth, 1969, 76, 444.

$1 s$ Aguilo, F., Jr., Vega, L. A., Haddock, L., Rodriguez, O., Jr., Acta Endocrinologica, 1969, 60, suppl. 137.

14 Fabian, M., Forsling, M. L., Jones, J. J., and Pryor, J. S., fournal of

Physiology, 1969, 204, 653.
15 Robertson, G. L., Klein, L. A., Roth, J., and Gorden, P., Proceedings of the National Academy of Sciences, 1970, 66, 1298.

${ }^{10}$ Edwards, C. R. W., Chard, T., Kitau, M. J., and Forsling, M. L., fournal of Endocrinology, 1970, 48, 11 .

${ }^{17}$ Price, J. D. E., and Lauener, R. W., Fournal of Clinical Endocrinology and Metabolism, 1966, 26, 143.

10 Dashe, A. M., Cramm, R. E., Crist, C. A., Habener, J. F., and Solomon, D. H., Fournal of the American Medical Association, 1963, 185, 699.

10 Miller, M., Dalakos, T., Moses, A. M., Fellerman, H., and Streeten, D. H. P., Annals of Internal Medicine, 1970, 73, 721 .

D. H. P., Annals of Internal Medicine, 1970, 73, 721.

${ }^{21}$ Garrod, O., in The Pituitary Gland, ed. G. W. Harris and B. T. Donovan, vol. 3, p. 662 . London, Butterworths, 1966 .

22 de Wardener, H. E., and Herzheimer, A. W., Fournal of Physiology, 1957, 138, 35P.

ss Schaison, G., Presse Médicale, 1971, 79, 561

s4 Crawford, J. D., and Kennedy, G. C., Nature, 1959, 183, 891.

${ }^{25}$ Arduino, F., Ferraz, F. P. J., and Rodrigues, J., Fournal of Clinical Endocrinology and Metabolism, 1966, 26, 1325.

"B Berndt, W. O., Miller, M., Kettyle, M., and Valtin, H., Endocrinology, $1970,86,1028$.

\section{One Hundred Years Ago}

From the British Medical fournal, 13 April 1872

WHY ARE CASES OF JOINT-DISEASE INVARIABLY WORSE DURING THE WARM MOIST DAYS OF WINTER?

Sir,-This question, recently propounded by the Editor of the British Medical fournal, at the termination of some remarks on Mr. Wood's experience at King's College Hospital with reference to joint-affections, may have some light thrown on it by the following considerations. The rustic is informed by his sensations, and the dweller in towns by his barometer and hygrometer, concerning the coming weather. The former is of opinion that toothache, cornache, and pains of the joints; and the latter, that a decrease in the pressure, an excess of humidity, and an increase of the temperature of the air, are precursors of foul weather. Meterologists all know that the warm and moist equatorial current is generally accompanied in winter by a decrease of barometric pressure. How clearly did the great Jenner embody in a few lines of verse. "On the Signs of Rain," the effects of these atmospheric changes:

"Hark! how the chairs and tables crack, Old Betty's joints are on the rack."

The aching of corns is as readily accounted for as the cracking of chairs and tables; for both are evidently the result of the increase of the amount of moisture in the air. The great alterations in size which epithelial and ligneous structures undergo by the addition or subtraction of moisture are well known; what are the changes in the body when it is exposed to low barometric pressure?
Richardson, Hewson, and others tell us that there is a tendency to exudation of fluid from wounded surfaces, a feebleness in the healing of wounds, a susceptibility to disturbance in the body generally, and a proneness to the production of secondary fever by the absorption of discharges which have undergone some decomposition. The outcome of these facts has been the establishment of the law, that no important surgical operation should be performed when the barometer is low, or when it is steadily falling. The principal effect, however, of diminished pressure of the atmosphere is distension of the capillaries. We all recognise as one of the exciting causes of apoplectic seizures a rapid diminution of atmospheric pressure, producing a sudden capillary engorgement. An exacerbation of the symptoms in cases of joint-disease may be due, perhaps to the same meterological change acting in a manner which may be thus explained. In the solid inelastic articular expansions of the bones, which are surrounded by firm inextensile textures forming the joints, the minute nerves, shown by Kölliker and others to permeate the cancellous and compact structures in company with vessels, are pressed by these vessels when enlarged against the unyielding walls of the channels through which they pass. Although the nerves of bones do not generally afford healthy individuals any conscious sensations; yet, in diseases of the joints, the bones, when congested, or the seat of inflammation, become painful. ...

I am, etc., CORNELIUS B. FOX, M.D., F.M.S. Scarborough, March 1872. 